\title{
THE DIMENSIONS OF RESPONSIBILITY OF THE TEAM PHYSICIAN
}

\author{
J. A. BULLARD, M.B., B.S. \\ 2027 Urbana Road, Calgary, Alberta \\ Family Physician, Consultant in Athletic Medicine, Teams Physician, University of Calgary \\ Canadian Team Physician, World Student Games, 1973 (Moscow)
}

\begin{abstract}
In an ideal situation, the responsibilities of a team physician begin with the first meeting of the club or organization. At that time the physician can discuss with the president of the club, athletic director, or committee members or coach, exactly and precisely where he stands in future arrangements. The termination of his responsibility comes at the end of the season with certain exceptions. Some injuries occurring during the season may require continued supervision before the athlete can be considered to have made a maximal recovery and some very necessary planning must be made for the next season, particularly in areas of protective equipment and pre-season conditioning. Between the initial contact with the organization and final clearance with fitness of the athletes at the end of the season lies a wealth of responsibility. Many factors will influence the degree of acceptance of this considerable challenge by the physician.
\end{abstract}

SUMMARY

Physicians have become increasingly involved in sports in recent years. No longer can this association be a casual one. It carried with it many responsibilities, the extent of which grow with the degrees of involvement.

Some of these responsibilities are discussed as they apply to the Team Physicians.

\section{ORGANIZATIONAL MEETING}

For a smooth running association with sports teams, whether they be involved in football, hockey, gymnastics, track or dance, it is essential for all concerned to recognize their duties. In this I include coach, manager, trainer, physician, as well as athlete. At the university level we are obviously more fortunate, having a central core from which to work, as well as very knowledgeable coaches, trainers and a deeper involvement by athletes, many of whom may aspire to the professional ranks. At The University of Calgary we have developed administrative policies regarding athletic medicine, including an organizational chart which clearly tabulates the duties of each member.

At other levels of participation, such as community sport, this ideal situation probably will not exist. Some definite understanding must, however, be reached. As a team physician it is irresponsible casually to attend, for example, a hockey game, without notifying the coach of your arrival, sitting in the stands without a bag containing at least the essentials to provide treatment for the injured and, above all, not knowing the health status of the players.

Whether one carries out a medical evaluation oneself, as official team physician, or ensures that it has been done by others, must be the doctor's decision, as discussed later. There are, however, certain disease conditions of which the team doctor must be aware. These include diabetes, epilepsy and a number of disqualifying conditions applied particularly to contact sport.

\section{Totally Disqualifying Conditions ${ }^{1}$}

A. Absolute. Those unable to participate in contact, but usually fit for non-contact competition.

1. Loss of one of a certain pair of organs, e.g. kidney and eye.

2. History of three or more concussions with loss of consciousness.

3. Persisting elevation of blood pressure (at rest over 160/100).

4. A long neck in American Gridiron football players and a history of previous fractures or dislocation with nerve root involvement.

B. Temporary. These may be recategorized after correction of the defect, but at the time are usually unfit for any athletic participation except remedial exercises.

1. Chronic infection, e.g. tuberculosis or osteomyelitis.

2. Infectious hepatitis and infectious mononucleosis.

3. Orthopaedic defects, e.g. certain back problems; Osgood-Schlatter's disease.

4. Hernia and cryptorchidism. 


\section{Relatively Disqualifying Conditions}

These conditions vary with each patient and must be judged on an individual basis by the physician.

1. Cardiovascular-renal disease. A history of rheumatic fever does not disqualify unless persistent heart damage is found.

2. Diabetes and epilepsy. Both conditions need to be well controlled with the appropriate medications and proper dosage. Swimming always presents a hazard to an epileptic and close supervision must be arranged. Recent views regarding epilepsy and contact sport have changed completely and now allow the individual to participate, unless the condition appears aggravated.

3. Impaired vision. Contact lenses, particularly the soft variety, have solved some problems in sport but have introduced several others.

\section{Endocrine disturbances and obesity.}

5. Dermatological problems, e.g. athlete's foot, impetigo.

6. Orthopaedic problems such as recurring dislocations.

The conditions mentioned, naturally, can be added to or subtracted from according to the sport, the severity of the problem, and the judgment of the physician.

Other facts, of which knowledge can be most useful in carrying out the duties of a team physician, include recent recovery from infections or injury which require adequate evaluation before permitting the athlete to continue. Some members of a community organization may, in their efforts to "get the show on the road," be casual about such coverage. The team physician should not be party to it. Among the most important considerations required of the coach, trainer, and athlete, is adequate communication with the physician. Changes in times, venue and travel arrangements, injuries requiring examination and evaluation for fitness to play, may have to be fitted into the physician's very tight schedule. Neither he nor his nurse appreciate extra work because of the failure of someone in their organization to keep them informed.

Much is said of the golf widow and the wives and families of husbands spending much of their time away from home. The team physician can find that his activity fits into this category, or he can enjoy many hours together with his wife and family as he carries out his duties.

In this particular section of responsibility, it is essen- tial therefore that ground rules be made between the organizers, the athlete, the physician, and his own family before the first training session.

\section{PRE-SEASON MEDICAL EVALUATION}

The Committee on the Medical Aspects of Sports of the American Medical Association states the need as follows: ${ }^{2}$

The realth examination is a basic part of the preparation of the athlete for sports participation. Medical evaluation goes beyond the health examination, however, to assure each athlete the best possible health guidance. Emphasis is to be placed upon individual needs and capabilities with the ultimate goal of furthering the health and development of the athlete. The aims of the examination include:

(1) To determine the health status of candidates prior to exposure to participation and competition.

(2) To provide appropriate medical advice to promote optimal health and fitness.

(3) To arrange for further evaluation and prompt treatment of remedial conditions.

(4) To counsel the atypical candidate as to the sports or modifications of sports which for him would provide suitable activity.

(5) To restrict from participation those whose physical limitations present undue risk.

In most instances, there are two choices to make; either to ask the family physician to carry out the pre-season medical examination and to give a written report, or for the team doctor to evaluate every member of the team himself. A certain amount of misunderstanding by local physicians can occur if the latter method is adopted, but the final decision must be influenced by the degree of responsibility the team physician decides to accept.

If he plans to carry out the medical evaluation himself, two approaches can be made in this very important area. Firstly, he can proceed with the physical examination, which must include an adequate history of previous illness as well as injury, previous surgery and a record of immunizations, particularly applied to tetanus vaccine where playing fields may be suspect as far as fertilization with animal manure is concerned. Examinations must be thorough and laboratory work should include haemoglobin, urinalysis, and chest $X$-ray. Secondly, this work can be accepted as carried out by the family physician and the team physician can concentrate upon an orthopaedic 
survey. This essentially includes an assessment of joints, muscles, and tendons, and can be enlarged upon to include areas of concern as they apply to the individual under review. It is quite surprising how many defects can be picked up in such a survey, which can in itself be done fairly rapidly. My own observations in one football team at The University of Calgary were as follows:

Players examined

Abnormalities noted
Chronic
Acute
Chronic
Knees (ligaments) - laxity in
Upper limb - restricted supination
Spine - restricted range of movement
Acute
Trochanteric bursitis
Shin splints
Groin strain

Baumann $^{3}$ in his study has demonstrated a similar high incidence of abnormalities. The value of this analysis is well demonstrated in the event of acute joint injury or re-injury. The physician having prior knowledge of a joint can make a far more accurate assessment of the damage recently sustained. Medical examination for sports participation is subject to many problems and the team physician can probably solve them all.

1. Financial responsibility may cloud the issue, as Medicare in the U.S.A. and Canada does not cover third party examinations. In some provinces an annual check up is permitted and, provided the parent signs the note for the coach, all is well.

2. Routine examinations for sport are given low priority by many family physicians and athletes find that they have to wait a week or two for an appointment. Their individual problems may even then go unanswered.

3. Assessment of laxity of ligaments varies from physician to physician, as does the opinion regarding treatment and future involvement of the athlete. This is well demonstrated by the variations in the treatment of a simple ankle sprain, as well as the advice given by physicians for and against participation of an epileptic patient in body contact sports. ${ }^{4}$

The team physician must make a thorough assessment, mentally and physically, of every member of a team. The psychiatric aspect must be considered, although problems in this area will not necessarily be revealed with a single interview. Emotional problems will become more apparent with contact between physician and athlete at practices and games. A good example of this area of involvement can occur in contact sport. The individual may feel that he must play the game, either as a result of pressure from his girl friend, parents, or peer group. Realizing his mistake, the player must now save face. An injury usually occurs and becomes exaggerated out of all proportion and the question "Do you think I will be able to play again this year?"' arises. Team physicians should recognize this situation and provide the escape as soon as possible.

\section{PRACTICE AND GAME COVERAGE}

It would be naive to think that many team physicians can attend all practices and games. I would recommend, however, that they be aware of the methods of conditioning being used, the type of equipment, and so on. They can arrange an adequate means of communication between the trainer and themselves for day-to-day consideration of injuries. Some over-enthusiastic coaches can be quite blind to the injuries they are causing during practice. Many examples come to mind and they help to emphasize this point.

1. Pole vaulting in a gymnasium using an inflatable high jump landing mat led to three athletes being injured in a period of half an hour, including a dislocated elbow, Colles' fracture of the wrist, and severe bruising of the back.

2. Repeated sessions of moving sideways across the gym at speed for basketball conditioning led to severe bilateral calf muscle strain, including haematomas in three veteran players - the results of new training techniques by a new coach.

3. A piece of equipment designed to imitate an oncoming player was released prematurely, hitting the victim as he prepared to get in the ready position. He was severely concussed and developed obvious signs of cervical nerve root compression. His days as a player may be over.

Applying both to practice and games, the timing of meals is probably as important as the consideration of their content. The physician should not interfere with the diet of players, unless they present with definite problems, such as nausea and vomiting prior to games, loss of weight or overweight. A coach may require guidance as to timing of meals prior to practice or games and this, of course, should be given by the physician. Similarly, fluid and electrolyte balance must always be considered in the presence of a hot, humid atmosphere. Team physicians must recognize the need for salt and water replacement, as well as the problems associated with the taking of excessive amounts of salt or cold water following exertion. Excess weight in the wrestler is still treated by starvation and dehydration. In no way 
can the physician accept this as a concept of physical fitness or suitable preparation for strenuous activity.

\section{GAME TIME}

For the physician, the game situation evolves around availability. The trainer tapes wherever necessary, attends to minor blisters, calluses, bruises, etc., and seeks the physician's advice as problems arise. Decisions regarding fitness of players to participate will hopefully have been made-well beforehand, but occasionaily final assessment is left until just before game time. The physician must therefore plan to be at the stadium or arena at least twenty minutes prior to the start of the game.

Injuries occurring on the field may be serious enough to require expert opinion before moving the athlete. This particularly applies to head and back injuries. The team physician should not therefore be inaccessible in the stands, but be within easy reach of the bench and trainer. At the interval the physician and the trainer can get together and further assess and treat the injured players. In some instances, the coach may need to be notified of the ability of a player, taken out in the first half of the game, to participate further. The players, too, have a chance to concentrate on themselves and can be given reassurance or advice about any injuries they have sustained. At the end of the game the physician should be checking for all injuries and making the necessary arrangements, some immediate, some delayed. The sum total here is availability at all times, to the players, the coach, not to forget the anxious parent or wife who should come before any dealings with the news media.

\section{DOCTOR'S BAG}

A few words about the physician's bag and contents are in order. Much will depend on the sport and the degree of the physician's involvement. Suturing in the dressing room is an accepted practice in ice hockey but in most other sports can be left until after the game and the athlete taken to a casualty department for attention. Some drugs are useful on trips away from home and certain injectable preparations are invaluable. These may include Dimenhydrinate ("gravol"), adrenalin, valium, codeine, an anti histamine and morphine. Contact sport demands that the physician has adequate means to restore an airway. Clenched teeth associated with a tongue rolled to the back of the throat in an unconscious individual calls for prompt action as well as the right tools for the job. Among these are included a wooden spatula, tongue forceps, an airway, a large bore needle, and an oral screw. Useful instruments such as a hand mirror for locating contact lenses under the upper lid, splinter-removing forceps, and other implements can be invaluable and can be included according to individual taste.

\section{ADDITIONAL INVOLVEMENT}

\section{Personal Practice}

The deeper the physician becomes involved in sport, the more impression it makes on his own practice. Naturally, this applies to a greater degree to the family practitioner, as he has to deal with large numbers of patient. Athletes and their families become patients and this generally leads to a younger practice and a good doctor-patient relationship. Practices can be set up so that the nurse considers athletic injuries as urgent and fits them in immediately. The total success of this undertaking in many ways is dependent on cooperation from the physiotherapists in the area. We have coined a phrase "instant physio", which means that there is a distinction between acute and chronic conditions requiring physiotherapy and the acute will rapidly become chronic if they wait around too long. Arrangements with private physiotherapists or interested hospital departments can often be made.

\section{Vitamins, Diets and Drugs}

Enquiries about vitamin supplements, high protein diets, and other aspects of nutrition are frequently made by athletes. The physician must become well acquainted with current use and be prepared to provide a positive answer. Drugs, such as amphetamines, anabolic steroids, and other boosters, have no place in the physician's armamentarium. In spite of this fact, they are obtainable and used by athletes and the side effects must be recognized as well as adequately treated.

\section{Equipment}

The medical profession is gradually placing more emphasis on the preventitive aspect of medicine. The use and abuse of equipment is a prime example of the need for close observation and application of this principle. In Canada, helmets have recently received governmental attention and, apart from the suspect standards finally reached, we have at least succeeded in making it compulsory for helmets to be worn at most levels of ice hockey. Mouth and eye protectors are still optional, but team physicians should consider this type of equipment and become involved in its development. Flag posts, for example, should never consist of a rigid pole or sawn off hockey stick driven into the ground. A tightly packed scrum in rugby can impale a player on such an object. The coiled spring variety are readily available and should be used. Again, the observant team physician, always considering the best interests of his athletes, can spot dangers overlooked by the untrained eye. 


\section{Research}

From these few observations it is obvious that there is room for research in many areas. This may be on a very simple level, such as evaluating the injuries on a team, to a detailed study of the effects of a drug on certain athletic conditions. Many practising physicians would be prepared to work with those more research-orientated physiologists as they each in turn recognize the potential in this field.

\section{Further Education}

Finally, it becomes increasingly obvious to the team physician that there are areas of knowledge related to sport and medicine not taught in medical schools, nor found in regular medical text books. He must therefore consider joining the sports medicine association best suited to his needs, attend appropriate courses, and avail himself of the increasing number of books now published on the subject.

\section{CONCLUSION}

Whether he enjoys a certain amount of status with the job, the competitive nature of sports, or the challenge of making important decisions without the usual work up, the team physician has a great responsibility, the dimensions of which seem to grow with the degree of involvement.

\section{REFERENCES}

1. Alberta Medical Bulletin, (1968), 33, No. 1; 13.

2. American Medical Association, (1965), "A Guide for Medical Evaluation of Candidates for School Sports," Committee on the Medical Aspects of Sports."

3. BAUMANN, J. (1968), University of California, Santa Barbara. "Pre-Season Football Physical Examinations ... An Evaluation," Journal of American College Health Association, 17; 22, October.

4. LIVINGSTON, S. and BERMAN, W., (1974), "Participation of the Epileptic Child in Contact Sports", Journal of Sports Medicine, II, May-June, No. 3; 170. 